\title{
Additional pulmonary resection after pneumonectomy under ECMO support: a narrative review and representative case report
}

\author{
Dominik V. Flury, Sarah A. Deckarm, Gregor J. Kocher, Ralph A. Schmid, Jon A. Lutz \\ Department of Thoracic Surgery, Inselspital, Bern University Hospital, University of Bern, Bern, Switzerland \\ Contributions: (I) Conception and design: All authors; (II) Administrative support: All authors; (III) Provision of study materials or patients: All \\ authors; (IV) Collection and assembly of data: All authors; (V) Data analysis and interpretation: All authors; (VI) Manuscript writing: All authors; (VII) \\ Final approval of manuscript: All authors. \\ Correspondence to: Ralph A. Schmid. Division of General Thoracic Surgery, University Hospital Bern, 3010 Bern, Switzerland. \\ Email: ralph.schmid@insel.ch.
}

\begin{abstract}
Patients who have undergone previous pneumonectomy may develop new or second primary cancers, secondary cancers (metastases) or even recurrent malignant disease in the remaining single lung. It is a common misbelief that additional pulmonary resection in a single lung is not feasible. These cases should not be deemed unresectable solely due to the fact of new lesions in the remaining lung after contralateral pneumonectomy. Individual treatment approaches should be based on a multidisciplinary case discussion in specialized centers with high patient volume following meticulous preoperative evaluation and cardiopulmonary assessment. In patients with sufficient cardiopulmonary reserves, an aggressive approach with limited sublobar resection (segmentectomy or wedge resection) can be beneficial and provide good functional and oncological outcome as well as maintenance of quality of life. In this narrative review the evaluation, the management as well as the outcome of additional pulmonary resection after contralateral pneumonectomy with benefits of using extracorporeal membrane oxygenation (ECMO) during these surgical procedures is discussed. In addition, a patient that we encountered in our clinical work is dissected in further detail. This case elucidates numerous critical considerations that the interdisciplinary team must make and the challenging decision-making process in balancing feasibility, individual risks and expected benefits. The surgical methodology employed and the outcomes are also highlighted.
\end{abstract}

Keywords: Extracorporeal membrane oxygenation (ECMO); pneumonectomy; thoracic surgery; video-assisted thoracic surgery (VATS); uniportal VATS

Received: 18 October 2020; Accepted: 26 February 2021.

doi: $10.21037 /$ ccts-20-169

View this article at: http://dx.doi.org/10.21037/ccts-20-169

\section{Introduction}

\section{Extracorporeal membrane oxygenation (ECMO) in thoracic surgery}

For pulmonary resections selective mechanical ventilation utilizing a left or right double lumen endotracheal tube (DLT) is regularly used, offering a safe approach and access to hilar structures for precise dissection. In challenging cases including severe pulmonary hemorrhage (e.g., ruptured pulmonary arteriovenous malformation), blunt chest trauma, in patients with marginal or insufficient pulmonary reserve (e.g., respiratory failure, ARDS) or in complex tracheo-bronchial reconstructions as well as in single-lung surgery, one-lung ventilation with intermittent apnea phases might not be sufficient and therefore might not be the optimal anesthesiologic approach in selected cases.

In 1996 Horita et al. reported the first pulmonary resection using ECMO during two carinal resections as well as reconstructions (1). Yet, extracorporeal life support (ECLS) such as elective use of ECMO in general thoracic surgery is rarely used outside of lung transplantation, but 
can allow good surgical exposure and visibility, improved oxygenation as well as removal of carbon dioxide under the specific circumstances mentioned above. In some situations, a jet, in field or cross ventilation (e.g., in complex tracheobronchial surgery) or even cardiopulmonary bypass can be alternative approaches $(2,3)$.

For complex tracheo-bronchial reconstructions or in single-lung surgery, selective intermittent mechanical ventilation of one or two lobes with apnea phases using a bronchial blocker or jet-ventilation may not offer the same amount of surgical exposure compared to ECMO or cardiopulmonary bypass (2-15). Additionally, ECMO can ensure gas exchange, hemodynamic stability and good hemostasis with a clean and calm operative field. Furthermore, it might even reduce the risk of potential tumor cell spread (compared to jet-ventilation) $(5,12)$.

\section{Single lung surgery}

Performing an additional resection after pneumonectomy is not solely related to lung cancer surgery. In literature, there are reported cases of bronchiectasis $(16,17)$, pulmonary metastasis in colorectal adenocarcinoma (6) and fibrosarcoma (18) requiring additional resection after contralateral pneumonectomy.

In single-lung surgery, mechanical ventilation can be extremely difficult. Mercier et al. recommends performing resection after contralateral pneumonectomy using mechanical ventilation with high-flow oxygen and intermittent apnea phases. This technique is considered reliable and effective and allows for precise hilar dissection as well as mediastinal lymphadenectomy (19). It is important to emphasize that Mercier et al. preferred either open thoracotomy or even median sternotomy as a surgical approach in patients with resection in a single-lung, while stating that the limited ability to sustain apnea phases for longer than a few minutes makes video-assisted thoracic surgery (VATS) impossible (19). Other authors also reported the use of high-flow oxygen or selective ventilation of one or two lobes as a possible approach in single-lung surgery, but in case of respiratory failure and the consequent need of lung ventilation the surgical procedure might become very challenging (2-15).

In literature, less than 200 cases of pulmonary resections (lobectomies, segmentectomies, single and multiple wedge resections) after contralateral pneumonectomy were published (4,6,7,12,13,16-34). Most frequently, these were sublobar resections (especially wedge resections) and were performed by thoracotomy without the use of ECLS (16-29,32-34). Only a few case reports of ECMO-assisted pulmonary resection after contralateral pneumonectomy exist $(4,6,12,13)$. Spaggiari et al. reported the use of femorofemoral cardiopulmonary bypass in a single-lung surgery performed through posterolateral thoracotomy (30). Gu et al. reported the use of an adapted DLT for an anatomical segmentectomy (right segment 3) using the uniportal VATS technique (31). The use of an ECLS provides a clean and calm operation field and offers the possibility to perform major anatomical resections using minimal invasive approaches such as VATS. In 2017 Kocher et al. reported the first minimally invasive major anatomical resection performed in 2016 under ECMO with the use of a single dual lumen cannula (uniportal VATS, right segment 1 resection) (7).

Our experience of the use of ECMO in thoracic surgery is derived from emergency trauma surgery, tracheabronchial surgery and single lung surgery. In the last few years we utilized ECMO in patients with severe blunt chest trauma (for instance, due to a demolition accident), in severe pulmonary bleeding (for instance, in the case of ruptured pulmonary arteriovenous malformations in a young pregnant women with hereditary hemorrhagic telangiectasia also known as Osler-Weber Rendu syndrome), in tracheo-bronchial surgery with bronchoplasty in children as published by Scholl et al. in 2019 (8) and also in single lung surgery, where conventional mechanical ventilation techniques were limited as mentioned before (7).

We present the following article in accordance with the Narrative Review reporting checklist (available at https:// ccts.amegroups.com/article/view/10.21037/ccts-20-169/rc).

\section{Methods}

To determine the current clinical evidence of perioperative evaluation and management of additional pulmonary resection under ECMO support we searched two electronic databases (PubMed and the Cochrane Library) for articles from 1973 to September 2020 as well as the most recent guidelines in English and German language. The date of the last search was September 6, 2020.

Randomized controlled trials comparing therapeutic approaches and evaluation of long-term outcome might be nearly impossible considering the rarity and the individual differences of these cases. Therefore, from the limited data published, we included all published and reported cases, series and reviews, found in the above-mentioned databases, 
to identify optimal preoperative assessment, survival rates and therapeutic approaches of the specific scenarios in single lung surgery.

We checked cross-references and searched references from all the mentioned guidelines, review articles and published series. The articles included were assessed for eligibility by all the authors.

\section{Case presentation}

\section{Medical bistory}

In this case, in part already published by Kocher et al., we report the course of a 47-year-old male patient, who was diagnosed with an intimal sarcoma of the left central pulmonary artery in 2003 (7). After multidisciplinary case discussion an extended left-sided pneumonectomy was performed (pT1b cN0 cM0 G2 R0) including partial pericardiectomy and reconstruction with a prolene polypropylene mesh as well as a radical resection of the pulmonary trunk and pulmonary semilunar valve followed by a bioprosthetic reconstruction of the resected areas as well as the pulmonary valve. The resection was performed under the use of ECMO. Complete mediastinal and hilar lymphadenectomy was not performed. Six years later the patient developed a retrosternal relapse in the manubrium. After four cycles of neoadjuvant chemotherapy (epirubicin and ifosfamide) resection was performed, followed by percutaneous radiotherapy (60 Gray).

\section{Preoperative assessment}

A computed tomography (CT) scan in 2016 revealed a single pulmonary nodule $(31 \times 18 \times 20 \mathrm{~mm})$ in the right upper lobe (apical segment) with contact to the mediastinum. The tumor showed intensive FDG-avidity in the positron emission tomography (PET) scan without any evidence of lymph node metastases or distant metastatic disease (Figure 1). The multidisciplinary tumor board recommended histopathologic assessment to establish the diagnosis of recurrence or a secondary tumor or even second primary cancer. Endobronchial ultrasound with transbronchial needle aspiration (EBUS-TBNA) confirmed a second relapse of the intimal sarcoma. To assess the operability as well as the likely postoperative morbidity and mortality in this patient, who has undergone previous pneumonectomy, a preoperative evaluation of lung function, cardiopulmonary exercise testing (CPET) and echocardiography was performed. The 60-year-old male was in excellent condition with an Eastern Cooperative Oncology Group (ECOG) performance status grade 0 and normal blood gas analysis while breathing room air. CPET showed a forced expiratory volume exhaled during in the first second $\left(\mathrm{FEV}_{1}\right)$ of 1.84 liters, which is $54.9 \%$ of predicted normal and a diffusing capacity of the lungs for carbon monoxide (DLCO) of $132 \%$. The preoperative value of $\mathrm{VO}_{2 \text { peak }}$ was $23.9 \mathrm{~mL} / \mathrm{kg} / \mathrm{min}$, qualifying for additional pulmonary resection with a predicted postoperative $\mathrm{FEV}_{1}\left(\mathrm{ppoFEV}_{1}\right)$ of 1.66 liters (49.4\% predicted) a predicted postoperative DLCO (ppoDLCO) of $118 \%$ and a postoperative $\mathrm{VO}_{2 \text { peak }}$ of $21.5 \mathrm{~mL} / \mathrm{kg} / \mathrm{min}$. Echocardiography including right heart catheterization showed a left ventricular ejection fraction of $60 \%$, bi-atrial dilatation and no increase in pulmonary artery pressure. After further multidisciplinary case discussion, the tumor board favored surgery with limited pulmonary resection (segmentectomy) over lobectomy to preserve as much lung parenchyma after the previous pneumonectomy as possible.

\section{Procedure}

After placement of a thoracic epidural catheter, general anesthesia was induced and standard monitoring installed. Veno-venous ECMO (vv-ECMO) was established using a percutaneous approach with a single cannula (Figure 2). Therefore, the $31 \mathrm{~F}$ and $31 \mathrm{~cm}$ bi-directional single cannula was inserted into the right internal jugular vein under transesophageal echocardiography guidance to ensure correct positioning. Prior to the installation of the ECMO circuit a bolus of 5,000 IU heparin was given. With the commencement of the ECMO circuit, the core body temperature of the patient was decreased to 34 degrees Celsius. Mechanical ventilation was stopped to achieve a collapse of the right lung allowing good surgical exposure and visibility during the surgery. Subsequently, the patient was placed in a left lateral decubitus position with his arms flexed and positioned towards the head on separate arm boards. The pleural cavity was accessed by a single $4 \mathrm{~cm}$ incision in the inframammary fold in the fifth intercostal space in a muscle-sparing technique without using a rib spreader. To maximize wound exposure and to keep the thoracoscopic lens clean as well as to protect the wound from contamination when removing the specimen (sarcoma), a wound protector was used as shown in Figure 3. To explore the thoracic cavity a $10 \mathrm{~mm} 30^{\circ}$ angled endoscope was employed. Lysis of pleural adhesions of 

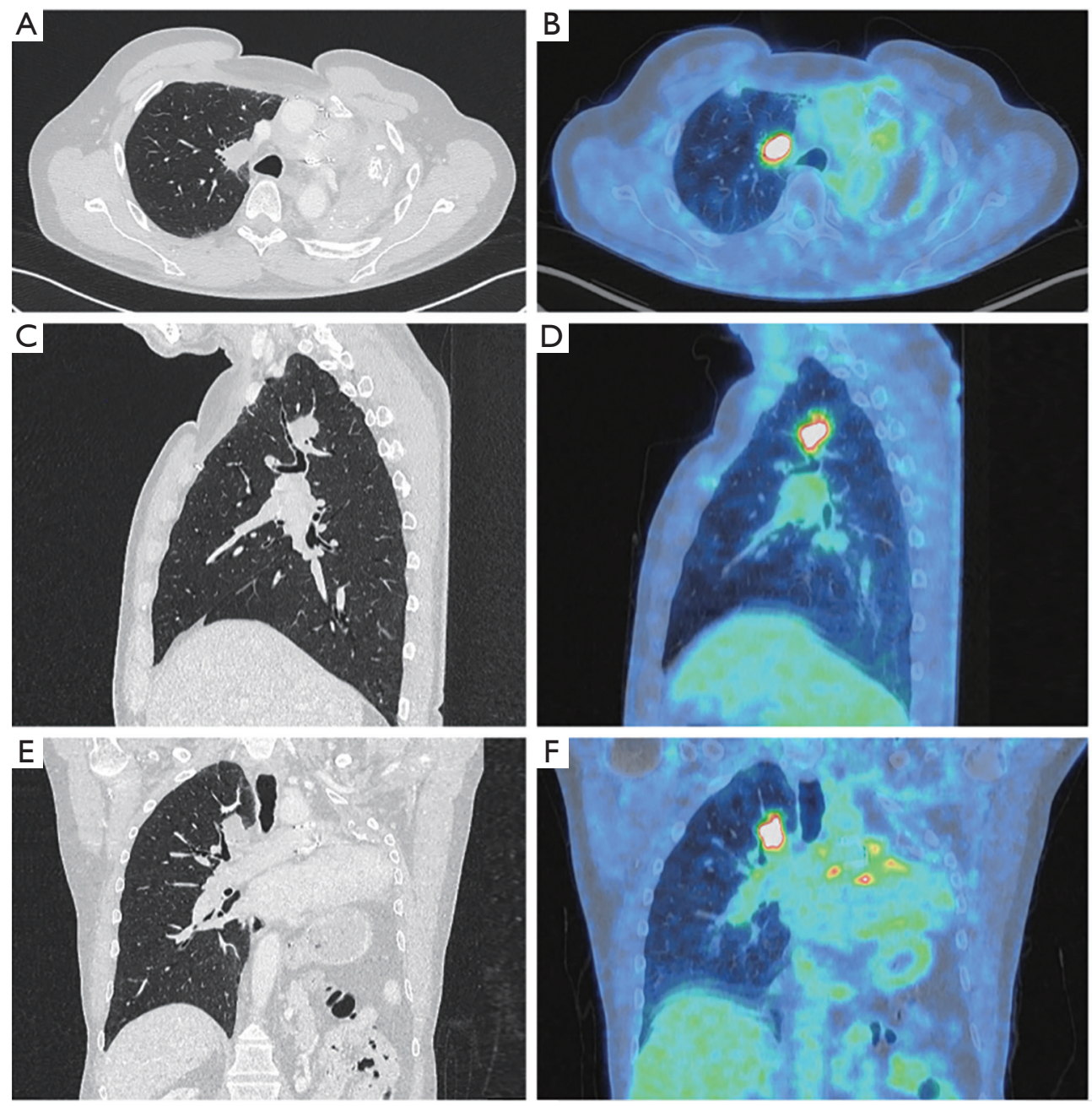

Figure 1 Tumor in the apical segment of the right upper lobe, CT and PET scan. Images (A) (CT scan) and (B) (PET scan): axial view; images (C) (CT scan) and (D) (PET scan): sagittal view; images (E) (CT scan) and (F) (PET scan): coronal view. CT, computed tomography; PET, positron emission tomography.

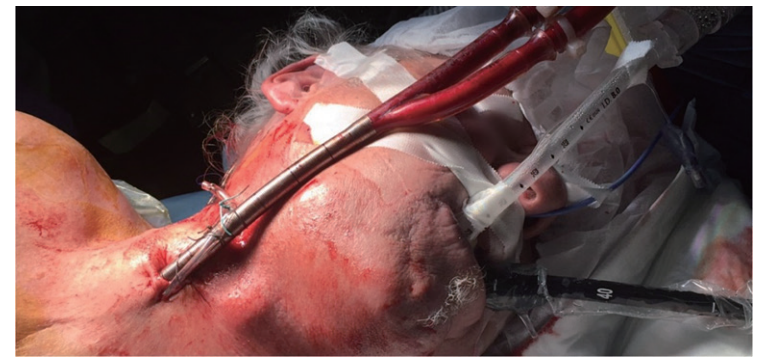

Figure 2 Veno-venous extracorporeal membrane oxygenation (vvECMO) established with a single cannula. the right upper lobe, chest wall and the mediastinum was performed to ensure complete mobility of the right lung. The targeted venous and arterial branches of the upper lobe were dissected, identifying V1 and A1. Mechanical vascular closure and division were performed for $\mathrm{V} 1$ and afterwards for A1 using an articulated vascular endostapler. Three mediastinal lymph nodes of station $4 \mathrm{R}$ were resected and after further hilar dissection, B1 was divided using the same vascular endostapling device. For identification of the segmental planes, the right lung was slightly reinflated 


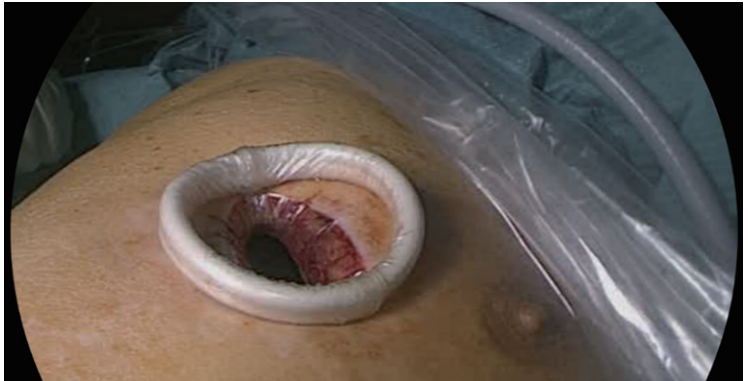

Figure 3 Uniportal VATS approach with a $4 \mathrm{~cm}$ incision and a wound protector. VATS, video-assisted thoracic surgery.

to show a demarcation of the targeted apical segment. Division of the pulmonary parenchyma was performed with another automatic endostapler. After the specimen was removed, a $24 \mathrm{~F}$ chest tube was placed through the same incision and mechanical ventilation was re-established. As the residual lung showed good expansion, a layered closure was performed, and the core body temperature was slowly re-increased to 36 degrees Celsius. The patient was successfully weaned from vv-ECMO after re-establishment of ventilation. Thus, the single cannula was removed, and the patient was immediately extubated in the operating theatre. The chest tube was connected to a $-5 \mathrm{cmH}_{2} \mathrm{O}$ suction device.

Time from induction until emergence from general anesthesia was 420 minutes in total including placement of the thoracic epidural catheter. Knife to skin time was 217 minutes including cannula removal, with a total vvECMO duration of 202 minutes. A single erythrocyte concentrate $(275 \mathrm{~mL})$ was transfused due to preoperative anemia (preoperatively $106 \mathrm{~g} / \mathrm{L}$, intraoperatively $92 \mathrm{~g} / \mathrm{L}$ ).

The patient was breathing spontaneously, and blood gas analysis was normal after extubation. The patient was transferred to our intermediate care unit.

On the second postoperative day (POD), the chest tube was removed with transfer of the patient to the thoracic ward on POD 3. The overall postoperative course was uneventful with discharge of the patient on POD 5 with a blood oxygen saturation of $98 \%$ while inhaling room air.

\section{Follow up}

The final histopathological analysis revealed a single micrometastasis $(1 \mathrm{~mm})$ in one of three lymph nodes in station $4 \mathrm{R}$ and a relapse of the intimal sarcoma $(2.5 \mathrm{~cm})$ in the apical lung segment with intravascular spread and invasion of the visceral pleura. A complete resection status (R0) was achieved and the tumor board recommended the first CT scan for follow-up to be performed 3 months after surgery. The first 4 weeks of follow-up were uneventful with later development of dyspnea on exertion and peripheral edema (primarily affecting the lids and the lower legs). The consequently performed CT scan and cardiac MRI showed a new mass $(15 \times 25 \mathrm{~mm})$ in the pulmonary trunk with highgrade stenosis and obstruction of the right ventricular outflow tract (RVOT). After multidisciplinary discussion, resection of the mass was favored, as it was highly suspicious for recurrence. Further cardiopulmonary assessments showed a mean pressure difference in the right ventricle of 67 millimeter of mercury $(\mathrm{mmHg})$ with a central venous pressure of $20 \mathrm{mmHg}$. These were considered contraindications for cardiothoracic surgery. The patient was treated with a combination of medications for heart failure and therapeutic anticoagulation was established. With limited options given to control the malignant disease and the progressive right heart failure, the patient deceased 2 months postoperatively.

All procedures performed in this study were in accordance with the ethical standards of the institutional and/or national research committee(s) and with the Helsinki Declaration (as revised in 2013). Ethical approval was not required because of the descriptive manner of this review and case report with limited participants (not more than 5). Written informed consent was obtained from the patient for publication of this manuscript and any accompanying images.

\section{Discussion}

\section{Additional pulmonary resection after pneumonectomy}

For patients with non-small cell lung cancer (NSCLC), radical anatomical surgical resection provides the best longterm survival, especially in patients with early-stage disease (stage I and II) (35-41). In patients with poor pulmonary reserve or major comorbidities with contraindications for lobectomy, sublobar resection with either segmentectomy (T1 a and T1b, tumor $<2 \mathrm{~cm}$ ) or wedge resection is appropriate $(35,36,42-47)$.

The recommended extent of anatomical resection in NSCLC depends on tumor size. In T1c-T4 tumors (>2 cm) lobectomy or pneumonectomy should be aimed for. The indication for pneumonectomy should only be considered when lung-sparing anatomical resection such as sleeve 
lobectomy are unlikely to achieve complete tumor resection $(35,36,39,42)$.

Patients who have undergone previous pneumonectomy are at risk of developing cancer (metastasis, second or multiple primary lung cancers) in the remaining single lung. After prior complete resection of a non-small lung cancer, the average risk per year of developing a new or a second primary lung cancer ranges between $1 \%$ and $6 \%$ $(4,19,48)$. These numbers slowly increased in recent years due to improvements in diagnostic possibilities including earlier detection during the postoperative follow-up by CT and PET scan. In addition, advancing treatment approaches such as the development of thoracoscopic pulmonary surgery in the last decades improved outcomes compared to open thoracotomy $(19,35,36,49-66)$. It is especially important but simultaneously challenging to differentiate multiple lung cancers. The clinical, radiological and histopathological or cytological findings should be taken into account when assessing patient cases and determine the individual treatment plan. Therefore, these patients should be discussed after completed staging in multidisciplinary boards in specialized centers with high patient volume. The multidisciplinary panels should include medical and radiation oncologists, pneumologists, experienced thoracic surgeons specialized in thoracic cancer surgery and thoracic pathologists. The findings of the histopathology or cytopathology are essential in identifying whether the novel tumor(s) are synchronous or metachronous primary lung cancers, multifocal lung cancers or metastases. However, certain challenges including an insufficiently small biopsy, the presence of only cytological specimens or the difficulty to approach depending on location of lesions may limit the quality of results and may imply unclear findings are reported $(19,20,36,37)$. In 1975 Martini et al. described empirical criteria for diagnosis to classify synchronous and metachronous secondary lung cancers (67). In the following decades, these criteria for diagnosis and differentiation of secondary primary lung cancers and metastases were slightly modified by Detterbeck et al. in 2003 (37,68). However, it remains necessary and crucial to consider all the clinical, radiological as well as the pathological features when forming an individual treatment plan for a patient with multiple pulmonary lesions.

Independent of age and medical fitness, an aggressive approach in a curative setting is key to obtain good overall survival rates and maintaining quality of life. Depending on localization, distribution and number of the multiple pulmonary lesions, a definitive local therapy by lung- sparing resection or as an alternative local stereotactic ablative radiotherapy (SABR) are therapeutic options $(19,20,35-37,39,42,48,69-72)$. However, in patients with only one lung, outcome, survival and even approaches may be different.

Compared to lung-sparing resections, the extent of a pneumonectomy is associated with higher morbidity and mortality and indications should be carefully made based on multidisciplinary recommendations regarding the operability of the patient according to pre- and postoperative pulmonary function, performance status and concurrent comorbidities (35-41,69,73,74).

Patients who underwent previous pneumonectomy in a curative intent are rarely considered for additional pulmonary resection due to the common misbelief that pulmonary surgery on a single lung is not feasible. Another misconception is that the higher risk of postoperative respiratory failure is seen as an absolute contraindication for subsequent pulmonary resection $(20,23,24,29,48)$.

Evidence of small retrospectives case series suggest that surgery in the remaining lung is a reasonable and rewarding option for well-selected cases. Therefore, these patients should not generally be excluded from an additional surgical approach $(4,6,7,12,13,16-34,72)$.

As mentioned above, the recommended extent of anatomical resection in lung cancer surgery is also based on tumor size. However, there might be the necessity of a compromise in surgical extent in lung cancer occurring in the single remaining lung. Lobectomy may not always be feasible and is not recommended because of the possibility of severe impairment of pulmonary function and quality of life, with possible exception of a middle lobectomy or lingulectomy (only two lung segments) $(19,23,24,26,69)$. Sublobar resection (segmentectomy or even wedge resection) is the preferred approach (16-29,32-34,69). Even if oncological principles might be compromised by the limited resection in high-risk patients with only a single lung, sublobar and preferably, non-anatomical resection might provide the best risk-benefit ratio with better pulmonary reserves and better quality of life $(20,23,24,69)$.

Ayub et al. analyzed the data of 165 patients who underwent additional pulmonary resection after contralateral pneumonectomy (20). The accumulated data originates from older small case series with overall 102 cases from 8 reports (22-29) plus a cohort of 63 cases identified by employing the Surveillance, Epidemiology, and End Results (SEER) database reported by Ayub et al. (20). Most of the older series did not report tumor 
size and/or have incomplete outcome reports. However, of all the reported 165 cases, 13 received lobectomies and 152 patients underwent sublobar resection with at least 18 single segmentectomies, 3 bi-segmentectomies, and one segmentectomy of the lower lobe basal segmental group (20-29). The sublobar resections included both wedge resections and segmentectomies (20-29). Regarding the extent of resection, lobectomies were associated with lower survival rates compared to sublobar resections (segmentectomy and wedge resection) (19,20,24,27-29) with the possible exception of a middle lobe or lingular resection (bisegmentectomy being the permitted maximal extent of resection) $(19,23,24,26,69)$. Other authors only reported series of cases with sublobar resections $(22,23,25)$. Massard et al. discussed four cases with two lobectomies performed through sternotomy, one segmentectomy through sternotomy and one wedge resection performed via thoracotomy (26).

The overall perioperative $(1$ month) mortality ranged from $0 \%$ up to $28.6 \%$ for all resections with a $1-, 3-$ and 5 -year survival of $53-87 \%, 35-63 \%$ and $30-50 \%$, respectively (20-29). Ayub et al. also reported a perioperative mortality of $10.7 \%$ for sublobar resection and $14.3 \%$ for lobectomy. While not statistically significant, it is interesting to note that the overall median survival was 42 months for the 56 sublobar resections versus only 18 months for the seven lobectomies performed. Thus, sublobar resection is preferred over lobectomy to achieve beneficial outcomes including survival, pulmonary function and quality of life. Median survival for resected metachronous tumors was 40 vs. 28 months in resected metastatic cancers (20). These findings are similar to the results discussed by Mercier $e t$ al. in an analysis of the same 8 reports of overall 102 patients (22-29) including the higher postoperative mortality for lobectomy $(33 \%)$ vs. sublobar resection $(6.2 \%)(19,20)$.

Due to classifying wedge resections and segmentectomies together as sublobar resections, no statement or differentiation can be made regarding the specific outcomes of these two procedures.

The reported data suggests the highest benefit of limited resection in a single lung in a subgroup of highly selected patients with small tumors (T1a and T1b, tumor $<2 \mathrm{~cm}$ ), early-stage disease (stage I-II) as well as in metachronous lung cancers (20).

Whether SABR or additional pulmonary resection may provide similar or better outcomes remains unclear because the reported series do not compare surgical with non-surgical approaches (20). Some authors reported a benefit in median overall survival following the surgical approach (39 months for surgery, in contrast to 20 months for radiotherapy alone) (69). Further investigation is needed but might be nearly impossible to achieve because of the rarity of these cases.

Besides pulmonary resection, evaluation of the hilar and mediastinal lymph nodes should be performed during lung cancer surgery through lymphadenectomy (19,36-41,75). This includes either mediastinal lymph node sampling (MLNS) or complete mediastinal lymph node dissection (MLND). Whether MLNS or MLND provides the better outcome stays controversial (35,40,76-78).

When considering additional pulmonary resection in a patient with a single lung, it is crucial to discuss whether the individual patient can benefit from additional surgery in terms of oncological outcomes and prognosis. It is especially significant to understand that a compromise in the form of a limited resection may have to be made in order to preserve enough pulmonary reserves postoperatively to maintain the patient's daily activities and have an acceptable quality of life $(20,29)$. Indeed, as mentioned above, sublobar resection might have better outcomes than lobectomy $(19,20)$. Therefore, a meticulous preoperative evaluation of lung function, CPET and echocardiography is recommended to assess postoperative morbidity and mortality when planning pulmonary resection in general. This should routinely include the $\mathrm{FEV}_{1}$ and the DLCO including its ppoFEV as well as the ppoDLCO $(19,20,69,74,75)$. Brunelli et al. generally recommend a ppoFEV $V_{1}$ and a ppoDLCO of at least $30 \%$ as a high-risk threshold (74). Other authors suggest $40 \%$ as a cut-off value $(19,20,75)$. It is important to emphasize that the ppoFEV $V_{1}$ and ppoDLCO should not be used alone as predictors of complications, hence, CPET should be complementary. A preoperative value of $\mathrm{VO}_{2 \text { peak }}$ greater than $75 \%$ predicted or $>20 \mathrm{~mL} / \mathrm{kg} / \mathrm{min}$ qualifies for pneumonectomy, while a preoperative $\mathrm{VO}_{2 \text { peak }}$ lower than $35 \%$ predicted or $<10 \mathrm{~mL} / \mathrm{kg} / \mathrm{min}$ indicates high risk for any extent of resection. A predicted postoperative value for $\mathrm{VO}_{2 \text { peak }}$ lower than $10 \mathrm{~mL} / \mathrm{kg} / \mathrm{min}$ is associated with a very high morbidity and mortality $(19,20,74,75)$. Additional echocardiography is paramount to evaluate right heart function and pulmonary hypertension $(19,20,69)$. Right heart dysfunction and elevated pulmonary artery pressure might be seen as contraindications for additional pulmonary surgery, because of potential worsening after resection and reduction of pulmonary vascular bed resulting in an increase of pulmonary artery pressure $(19,20,69)$. Furthermore, concurrent medical comorbidities should be assessed. 
In summary, a comprehensive and systematic patient evaluation is a critical step in determining the potential benefits and risks a patient may face in single lung surgery after previous contralateral pneumonectomy.

\section{Conclusions}

Additional pulmonary resection after contralateral pneumonectomy remains both a technical and an oncological challenge.

The use of ECMO in single lung surgery offers good surgical exposure and visibility while ensuring adequate oxygenation. Alternative approaches such as the use of bronchial blockers with intermittent apnea phases or jetventilation may be limited, especially in terms of providing sufficient surgical exposure for minimally invasive thoracoscopic surgery.

Limited sublobar resection (segmentectomy or wedge resection) is the preferred approach preserving as much lung tissue as possible with good functional outcome, good quality of life and possible long-term survival, especially in early stage and/or metachronous NSCLC. Therefore, these procedures should only be performed in highly selected patients after individual case discussion in multidisciplinary boards including medical and radiation oncologists, pneumologists and experienced thoracic surgeons specialized in thoracic cancer surgery. Patients not qualifying for a surgical approach can benefit from SABR.

ECLS offers a viable alternative for performing additional resections, especially anatomical resections, using minimal invasive approaches such as VATS by establishing a clean and calm operation field.

\section{Acknowledgments}

Funding: None.

\section{Footnote}

Provenance and Peer Review: This article was commissioned by the Guest Editors (Andrea Dell'Amore and Nizar Asadi) for the series "Mechanical Extracorporeal CardioRespiratory Supports in General Thoracic Surgery" published in Current Challenges in Thoracic Surgery. The article has undergone external peer review.

Reporting Checklist: The authors have completed the
Narrative Review reporting checklist. Available at https:// ccts.amegroups.com/article/view/10.21037/ccts-20-169/rc

Conflicts of Interest: The authors have completed the ICMJE uniform disclosure form (available at https://ccts. amegroups.com/article/view/10.21037/ccts-20-169/coif). The series "Mechanical Extracorporeal Cardio-Respiratory Supports in General Thoracic Surgery" was commissioned by the editorial office without any funding or sponsorship. GJK serves as an unpaid editorial board member of Current Challenges in Thoracic Surgery from September 2019 to August 2021. The authors have no other conflicts of interest to declare.

Ethical Statement: The authors are accountable for all aspects of the work in ensuring that questions related to the accuracy or integrity of any part of the work are appropriately investigated and resolved. All procedures performed in this study were in accordance with the ethical standards of the institutional and/or national research committee(s) and with the Helsinki Declaration (as revised in 2013). Ethical approval was not required because of the descriptive manner of this review and case report with limited participants (not more than 5). Written informed consent was obtained from the patient for publication of this manuscript and any accompanying images.

Open Access Statement: This is an Open Access article distributed in accordance with the Creative Commons Attribution-NonCommercial-NoDerivs 4.0 International License (CC BY-NC-ND 4.0), which permits the noncommercial replication and distribution of the article with the strict proviso that no changes or edits are made and the original work is properly cited (including links to both the formal publication through the relevant DOI and the license). See: https://creativecommons.org/licenses/by-nc-nd/4.0/.

\section{References}

1. Horita K, Itoh T, Furukawa K, et al. Carinal reconstruction under veno-venous bypass using a percutaneous cardiopulmonary bypass system. Thorac Cardiovasc Surg 1996;44:46-9.

2. Rinieri P, Peillon C, Bessou JP, et al. National review of use of extracorporeal membrane oxygenation as respiratory support in thoracic surgery excluding lung transplantation. Eur J Cardiothorac Surg 2015;47:87-94.

3. Makdisi G, Makdisi PB, Wang IW. New horizons of non- 
emergent use of extracorporeal membranous oxygenator support. Ann Transl Med 2016;4:76.

4. Heward E, Hayes T, Evison M, et al. Extracorporeal membrane oxygenation assisted segmentectomy for metachronous lung cancer after pneumonectomy. Ann Thorac Surg 2016;102:e187-9.

5. Lang G, Ghanim B, Hötzenecker K, et al. Extracorporeal membrane oxygenation support for complex tracheobronchial procedures $\uparrow$. Eur J Cardiothorac Surg 2015;47:250-5; discussion 256.

6. Gillon SA, Toufektzian L, Harrison-Phipps K, et al. Perioperative extracorporeal membrane oxygenation to facilitate lung resection after contralateral pneumonectomy. Ann Thorac Surg 2016;101:e71-3.

7. Kocher GJ, Zehnder A, Erdoes G, et al. Single-cannula, single-incision thoracoscopic anatomic segmentectomy after pneumonectomy. J Thorac Cardiovasc Surg 2017;154:e29-31.

8. Scholl H, Lutz JA, Kadner A, et al. Dynamic stenosis of the right main bronchus in a 3-month-old child: a tracheobronchial sleeve resection under venovenous extracorporeal membrane oxygenation. Eur J Cardiothorac Surg 2019;55:579-81.

9. Hoetzenecker K, Klepetko W, Keshavjee S, et al. Extracorporeal support in airway surgery. J Thorac Dis 2017;9:2108-17.

10. Rosskopfova P, Perentes JY, Ris HB, et al. Extracorporeal support for pulmonary resection: current indications and results. World J Surg Oncol 2016;14:25.

11. Redwan B, Ziegeler S, Freermann S, et al. Intraoperative veno-venous extracorporeal lung support in thoracic surgery: a single-centre experience. Interact Cardiovasc Thorac Surg 2015;21:766-72.

12. Lei J, Su K, Li XF, et al. ECMO-assisted carinal resection and reconstruction after left pneumonectomy. J Cardiothorac Surg 2010;5:89.

13. Owada-Ozaki Y, Matsumura Y, Suzuki H. VVECMO during subsequent segmentectomy after right pneumonectomy. J Surg Case Rep 2018;2018:rjy213.

14. Collins NF, Ellard L, Licari E, et al. Veno-venous extracorporeal membrane oxygenation and apnoeic oxygenation for tracheo-oesophageal fistula repair in a previously pneumonectomised patient. Anaesth Intensive Care 2014;42:789-92.

15. Grapatsas K, Schmid S, Haager B, et al. Short venovenous extracorporeal membrane oxygenation assisted segmentectomy for second primary lung tumor in a patient with insufficient respiratory function for one lung ventilation. Respir Med Case Rep 2018;24:176-8.

16. Judd DR, Vincent KS, Kinsella PW, et al. Long-term survival with the right lower lobe as the only lung tissue. Ann Thorac Surg 1985;40:623-4.

17. Kürklü EU, Le Roux BT. Left pneumonectomy and middle lobectomy for bronchiectasis. Thorax 1973;28:535-6.

18. Spaggiari L, Grunenwald D, Girard P, et al. Completion right lower lobectomy for recurrence after left pneumonectomy for metastases. Eur J Cardiothorac Surg 1997;12:798-800.

19. Mercier O, de Perrot M, Keshavjee S. Pulmonary resection after pneumonectomy. Thorac Surg Clin 2014;24:433-9.

20. Ayub A, Rehmani SS, Al-Ayoubi AM, et al. Pulmonary resection for second lung cancer after pneumonectomy: a population-based study. Ann Thorac Surg 2017;104:1131-7.

21. Toufektzian L, Patris V, Potaris K, et al. Is it safe and worthwhile to perform pulmonary resection after contralateral pneumonectomy? Interact Cardiovasc Thorac Surg 2015;20:265-9.

22. Grodzki T, Alchimowicz J, Kozak A, et al. Additional pulmonary resections after pneumonectomy: actual longterm survival and functional results. Eur J Cardiothorac Surg 2008;34:493-8.

23. Terzi A, Lonardoni A, Scanagatta $P$, et al. Lung resection for bronchogenic carcinoma after pneumonectomy: a safe and worthwhile procedure. Eur J Cardiothorac Surg 2004;25:456-9.

24. Donington JS, Miller DL, Rowland CC, et al. Subsequent pulmonary resection for bronchogenic carcinoma after pneumonectomy. Ann Thorac Surg 2002;74:154-8; discussion 158-9.

25. Spaggiari L, Grunenwald D, Girard P, et al. Cancer resection on the residual lung after pneumonectomy for bronchogenic carcinoma. Ann Thorac Surg 1996;62:1598-602.

26. Massard G, Wihlm JM, Morand G. Surgical management for metachronous bronchogenic cancer occurring after pneumonectomy. J Thorac Cardiovasc Surg 1995;109:597-600.

27. Westermann CJJ, van Swieten HA, de la Rivière $A B$, et al. Pulmonary resection after pneumonectomy in patients with bronchogenic carcinoma. J Thorac Cardiovasc Surg 1993;106:868-74.

28. Levasseur P, Regnard JF, Icard P, et al. Cancer surgery on a single residual lung. Eur J Cardiothorac Surg 1992;6:63940; discussion 641 . 
29. Kittle CF, Faber LP, Jensik RJ, et al. Pulmonary resection in patients after pneumonectomy. Ann Thorac Surg 1985;40:294-9.

30. Spaggiari L, Rusca M, Carbognani P, et al. Segmentectomy on a single lung by femorofemoral cardiopulmonary bypass. Ann Thorac Surg 1997;64:1519.

31. Gu Y, Duan R, Lv X, et al. Airway management of the right anterior segmentectomy through uniportal video-assisted thoracoscopic surgery (VATS) after left pneumonectomy by an adapted double-lumen endobronchial tube (DLT): a case report. BMC Anesthesiol 2019;19:82.

32. Liu Y, Cui P, Yang Z, et al. Right lower lobectomy eight years after left pneumonectomy for a second primary lung cancer. J Cardiothorac Surg 2013;8:46.

33. Quiroga J, Prim JMG, Moldes M, et al. Middle lobectomy after pneumonectomy. Asian Cardiovasc Thorac Ann 2009; 17:300-1.

34. Barker JA, Yahr WZ, Krieger BP. Right upper lobectomy twenty years after left pneumonectomy. Preoperative evaluation and follow-up. Chest 1990;97:248-50.

35. Flury DV, Minervini F, Kocher GJ. Heterogeneity of stage IIIA non-small cell lung cancer-different tumours, different nodal status, different treatment, different prognosis: a narrative review. Curr Chall Thorac Surg 2020. doi: 10.21037/ccts-20-97.

36. Ettinger DS, Wood DE, Aisner DL, et al. Non-small cell lung cancer, version 8.2020, NCCN Clinical Practice Guidelines in Oncology. [published 15 September 2020, accessed 27 September 2020]. Available online: https:// www.nccn.org/professionals/physician_gls/pdf/nscl.pdf

37. Kozower BD, Larner JM, Detterbeck FC, et al. Special treatment issues in non-small cell lung cancer: diagnosis and management of lung cancer, 3rd ed: American College of Chest Physicians evidence-based clinical practice guidelines. Chest 2013;143:e369S-99S.

38. Postmus PE, Kerr KM, Oudkerk M, et al. Early and locally advanced non-small-cell lung cancer (NSCLC): ESMO Clinical Practice Guidelines for diagnosis, treatment and follow-up. Ann Oncol 2017;28:iv1-21.

39. Leitlinienprogramm Onkologie (Deutsche Krebsgesellschaft, Deutsche Krebshilfe, AWMF): Prävention, Diagnostik, Therapie und Nachsorge des Lungenkarzinoms, Langversion 1.0. AWMFRegisternummer: 020/007OL. [published February 2018, accessed 27 September 2020]. Available online: http://leitlinienprogramm-onkologie.de/ Lungenkarzinom.98.0.html

40. PDQ® Adult Treatment Editorial Board. PDQ Non-
Small Cell Lung Cancer Treatment. Bethesda: National Cancer Institute. [Updated 24 September 2020, accessed 27 September 2020]. Available online: https://www.cancer. gov/types/lung/hp/non-small-cell-lung-treatment-pdq

41. National Institute for Health and Care Excellence. Lung cancer: diagnosis and management (NICE guideline 122). [published 28 March 2019, accessed 27 September 2020]. Available online: https://www.nice.org.uk/guidance/ NG122

42. Howington JA, Blum MG, Chang AC, et al. Treatment of stage I and II non-small cell lung cancer: diagnosis and management of lung cancer, 3rd ed: American College of Chest Physicians evidence-based clinical practice guidelines. Chest 2013;143:e278S-313S.

43. Villamizar N, Swanson SJ. Lobectomy vs. segmentectomy for NSCLC $(\mathrm{T}<2 \mathrm{~cm})$. Ann Cardiothorac Surg 2014;3:160-6.

44. Sienel W, Dango S, Kirschbaum A, et al. Sublobar resections in stage IA non-small cell lung cancer: segmentectomies result in significantly better cancerrelated survival than wedge resections. Eur J Cardiothorac Surg 2008;33:728-34.

45. Sienel W, Stremmel C, Kirschbaum A, et al. Frequency of local recurrence following segmentectomy of stage IA nonsmall cell lung cancer is influenced by segment localisation and width of resection margins--implications for patient selection for segmentectomy. Eur J Cardiothorac Surg 2007;31:522-7; discussion 527-8.

46. Landreneau RJ, Normolle DP, Christie NA, et al. Recurrence and survival outcomes after anatomic segmentectomy versus lobectomy for clinical stage I nonsmall-cell lung cancer: a propensity-matched analysis. J Clin Oncol 2014;32:2449-55.

47. Altorki NK, Yip R, Hanaoka T, et al. Sublobar resection is equivalent to lobectomy for clinical stage 1A lung cancer in solid nodules. J Thorac Cardiovasc Surg 2014;147:75462; discussion 762-4.

48. Loukeri AA, Kampolis CF, Ntokou A, et al. Metachronous and synchronous primary lung cancers: diagnostic aspects, surgical treatment, and prognosis. Clin Lung Cancer 2015;16:15-23.

49. Atkins BZ, Harpole DH Jr, Mangum JH, et al. Pulmonary segmentectomy by thoracotomy or thoracoscopy: reduced hospital length of stay with a minimally-invasive approach. Ann Thorac Surg 2007;84:1107-12; discussion 1112-3.

50. Whitson BA, Andrade RS, Boettcher A, et al. Videoassisted thoracoscopic surgery is more favorable than thoracotomy for resection of clinical stage I non-small cell 
lung cancer. Ann Thorac Surg 2007;83:1965-70.

51. Whitson BA, Groth SS, Duval SJ, et al. Surgery for earlystage non-small cell lung cancer: a systematic review of the video-assisted thoracoscopic surgery versus thoracotomy approaches to lobectomy. Ann Thorac Surg 2008;86:200816; discussion 2016-8.

52. Shaw JP, Dembitzer FR, Wisnivesky JP, et al. Videoassisted thoracoscopic lobectomy: state of the art and future directions. Ann Thorac Surg 2008;85:S705-9.

53. Ohtsuka T, Nomori H, Horio H, et al. Is major pulmonary resection by video-assisted thoracic surgery an adequate procedure in clinical stage I lung cancer? Chest 2004;125:1742-6.

54. Demmy TL, Nwogu C. Is video-assisted thoracic surgery lobectomy better? Quality of life considerations. Ann Thorac Surg 2008;85:S719-28.

55. Cattaneo SM, Park BJ, Wilton AS, et al. Use of videoassisted thoracic surgery for lobectomy in the elderly results in fewer complications. Ann Thorac Surg 2008;85:231-5; discussion 235-6.

56. Ilonen IK, Rasanen JV, Knuuttila A, et al. Anatomic thoracoscopic lung resection for non-small cell lung cancer in stage $\mathrm{I}$ is associated with less morbidity and shorter hospitalization than thoracotomy. Acta Oncol 2011;50:1126-32.

57. Yan TD, Black D, Bannon PG, et al. Systematic review and meta-analysis of randomized and nonrandomized trials on safety and efficacy of video-assisted thoracic surgery lobectomy for early-stage non-small-cell lung cancer. J Clin Oncol 2009;27:2553-62.

58. Villamizar NR, Darrabie MD, Burfeind WR, et al. Thoracoscopic lobectomy is associated with lower morbidity compared with thoracotomy. J Thorac Cardiovasc Surg 2009; 138:419-25.

59. Swanson SJ, Herndon JE, 2nd, D'Amico TA, et al. Videoassisted thoracic surgery lobectomy: report of CALGB 39802--a prospective, multi-institution feasibility study. J Clin Oncol 2007;25:4993-7.

60. Scott WJ, Allen MS, Darling G, et al. Video-assisted thoracic surgery versus open lobectomy for lung cancer: a secondary analysis of data from the American College of Surgeons Oncology Group Z0030 randomized clinical trial. J Thorac Cardiovasc Surg 2010;139:976-81; discussion 981-3.

61. Nicastri DG, Wisnivesky JP, Litle VR, et al. Thoracoscopic lobectomy: report on safety, discharge independence, pain, and chemotherapy tolerance. J Thorac Cardiovasc Surg 2008;135:642-7.
62. Paul S, Altorki NK, Sheng S, et al. Thoracoscopic lobectomy is associated with lower morbidity than open lobectomy: a propensity-matched analysis from the STS database. J Thorac Cardiovasc Surg 2010;139:366-78.

63. McKenna RJ Jr. New approaches to the minimally invasive treatment of lung cancer. Cancer J 2005;11:73-6.

64. Cao C, Manganas C, Ang SC, et al. A meta-analysis of unmatched and matched patients comparing videoassisted thoracoscopic lobectomy and conventional open lobectomy. Ann Cardiothorac Surg 2012;1:16-23.

65. Cao C, Manganas C, Ang SC, et al. Video-assisted thoracic surgery versus open thoracotomy for non-small cell lung cancer: a meta-analysis of propensity score-matched patients. Interact Cardiovasc Thorac Surg 2013;16:244-9.

66. Cheng D, Downey RJ, Kernstine K, et al. Video-assisted thoracic surgery in lung cancer resection: a meta-analysis and systematic review of controlled trials. Innovations (Phila) 2007;2:261-92.

67. Martini N, Melamed MR. Multiple primary lung cancers. J Thorac Cardiovasc Surg 1975;70:606-12.

68. Detterbeck FC, Jones DR, Kernstine KH, et al. Lung cancer. Special treatment issues. Chest 2003;123:244S-58S.

69. Bertoglio P, Lyberis P, Viti A, et al. Surgery after pneumonectomy: it is all a matter of balance. AME Med J 2017;2:166.

70. Aziz TM, Saad RA, Glasser J, et al. The management of second primary lung cancers. A single centre experience in 15 years. Eur J Cardiothorac Surg 2002;21:527-33.

71. Hamaji M, Allen MS, Cassivi SD, et al. Surgical treatment of metachronous second primary lung cancer after complete resection of non-small cell lung cancer. J Thorac Cardiovasc Surg 2013;145:683-90; discussion 690-1.

72. Angeletti CA, Mussi A, Janni A, et al. Second primary lung cancer and relapse: treatment and follow-up. Eur J Cardiothorac Surg 1995;9:607-11.

73. Brunelli A, Refai MA, Salati M, et al. Carbon monoxide lung diffusion capacity improves risk stratification in patients without airflow limitation: evidence for systematic measurement before lung resection. Eur J Cardiothorac Surg 2006;29:567-70.

74. Brunelli A, Charloux A, Bolliger CT, et al. ERS/ESTS clinical guidelines on fitness for radical therapy in lung cancer patients (surgery and chemo-radiotherapy). Eur Respir J 2009;34:17-41.

75. Donington J, Ferguson M, Mazzone P, et al. American College of Chest Physicians and Society of Thoracic Surgeons consensus statement for evaluation and management for high-risk patients with stage I non-small 
cell lung cancer. Chest 2012;142:1620-35.

76. Manser R, Wright G, Hart D, et al. Surgery for early stage non-small cell lung cancer. Cochrane Database Syst Rev 2005;(1):CD004699.

77. Allen MS, Darling GE, Pechet TT, et al. Morbidity and mortality of major pulmonary resections in patients with early-stage lung cancer: initial results of the randomized, prospective ACOSOG Z0030 trial. Ann Thorac Surg

doi: $10.21037 /$ ccts-20-169

Cite this article as: Flury DV, Deckarm SA, Kocher GJ, Schmid RA, Lutz JA. Additional pulmonary resection after pneumonectomy under ECMO support: a narrative review and representative case report. Curr Chall Thorac Surg 2021.
2006;81:1013-9; discussion 1019-20.

78. Darling GE, Allen MS, Decker PA, et al. Randomized trial of mediastinal lymph node sampling versus complete lymphadenectomy during pulmonary resection in the patient with N0 or N1 (less than hilar) non-small cell carcinoma: results of the American College of Surgery Oncology Group Z0030 Trial. J Thorac Cardiovasc Surg 2011;141:662-70. 